\title{
Energy potential of a single-fracture, robust, engineered geothermal system
}

\author{
G. Danko $\cdot$ A. Jobbik $\cdot$ M. K. Baracza $\cdot$ G. Varga $・$ I. Kovacs $\cdot$ V. Wittig
}

Received: 8 August 2019/Accepted: 18 December 2019/Published online: 15 February 2020

(C) The Author(s) 2020

\begin{abstract}
Engineered Geothermal Systems (EGS) are promising, but high-risk targets for baseline energy generation. Technology breakthrough is needed to lower the high risks from largely unknown geologic variables and the limited control of the coolant flow field underground. A new, robust EGS (REGS) arrangement and creation technology is reviewed featuring innovative fracture opening, stabilization and permeability control. The geometry, aperture support technique and coolant fluid flow isolation system are all robustly planned and created according the inventive concept. The new elements of the REGS technology are (1) the step-by-step creation, control, and tests of hydraulic fracturing to achieve a planar wing fracture or fractures osculating along the well trajectory; (2) fracture stabilization by hardening grouting injection to create a central support island in each planar wing fracture for zonal isolation; and (3)
\end{abstract}

G. Danko $(\bowtie)$

University of Nevada, Reno, 1664 Virginia Str, Reno,

NV 89557, USA

e-mail: danko@unr.edu

G. Danko · A. Jobbik · M. K. Baracza · G. Varga

Research Institute of Applied Earth Sciences, University

of Miskolc, Miskolc, Hungary

I. Kovacs

EU-FIRE Ltd., Budapest, Hungary

V. Wittig

GZB, Bochum, Germany well-fracture-well fluid circulation for geothermal energy extraction from single, or clustered planar fractures as geothermal heat exchangers. The paper reviews ongoing tests to prove the key components of the REGS geologic heat exchanger with stabilized, large fracture aperture and controlled flow zones for minimized opening pressure loss, seismicity and maximized energy extraction. Flow fields and heat transport are reviewed around zonal isolation of fracture flow by a grouted, blocking island for heat exchange. The robustness is reviewed for the step-bystep construction of a REGS. The paper reports new results from using numerical, coolant flow and heat exchange models to demonstrate the geothermal energy potential of a single REGS well drilled in hot, dry rock.

Keywords Robust EGS · Hydrofracture · Wing fracture $\cdot$ Single-well EGS $\cdot$ Single-fracture geothermal arrangement

\section{Introduction}

Geothermal energy generation from hot dry rock using EGS is the most promising (DOE 2006), yet the least successful in the U.S. and the world. The reasons are: (1) high risks from largely unknown geologic variables; (2) faults in the design concepts of currently used solutions relying on fracture opening by fluid 
pressure and/or shear aperture enhancement, making the joint's aperture an operational variable and thus prone to seismic activities with changing pressures and temperatures; (3) inherent loss of coolant water and energy due to excessive injection fluid pressure; and (4) large circulation energy loss in the currently known EGS solutions (Kumar and Ghassemi 2016; Jung 2013).

A technology tryout is underway (Danko et al. 2019), the basis of the paper, to prove the innovative fracture permeability creation and control. The geometry, aperture support technique and coolant fluid flow isolation system are all robustly planned and created according to an invention (UNR 2018; Danko et al. 2018). One, key element of robustness is the application of wing-type fracture geometry in which the fracture plane is parallel with the well from which it is created by hydrofracturing. The other key element is the step-by-step construction of a REGS (Robust EGS) with: directional drilling; wing-type mini-fracturing; testing for connectivity of each planar, wing fracture with the well; continuation of the construction and testing of a series of wing fractures along the directional drilled well whereas the well direction is continuously adjusted (if needed) to the planar directions of the fractures; and completion of the series of wing fractures with zonal insolation in each planar fracture by the injection of a grouted, blocking island between the intake and the extraction points of the wing fracture section. The key to the creation of a series of large, planar, wing fractures is a directionally-drilled well to follow each planar fracture, intersecting it at multiple points around a section at which the fracture approximates the osculating plane of the well, shown in Figs. 1 and 2. Further details of the explanation of achieving and testing the desired, planar, wing-fracture geometry for a REGS reservoir is omitted for brevity, referring to the technical disclosure published internationally (UNR 2018).

The new elements of the REGS technology are step-by-step tested and demonstrated in an international research cooperation with researchers from the USA and the EU (UNR 2018). Planning is underway for small-scale, directional drilling and fracturing experiments to achieve a planar wing fracture or fractures osculating along the well trajectory. Laboratory-scale, hardening grouting injection experiments are prepared to demonstrate the creation of a central support island in each planar wing fracture. Numerical

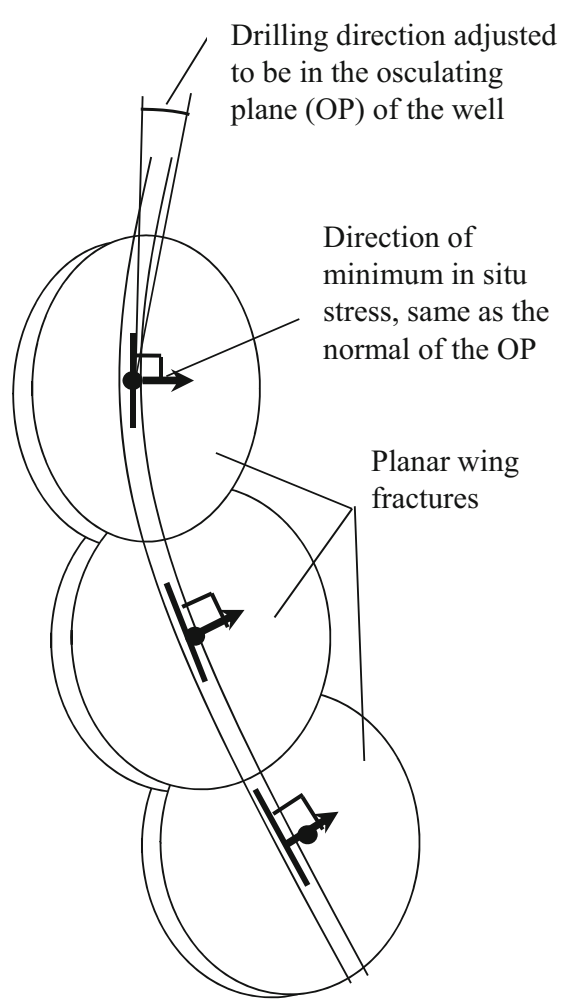

Fig. 1 Wing fractures along a main well

models are developed to scale the experimental results for the field-scale design of the REGS. Small-scale, experimental studies of well-fracture-well fluid circulation experiments are underway to verify the numerical model results for upscaling. Predicted scenarios are studied with scaled numerical models for fullscale REGS applications for large-scale applications in electrical power generation and heating in communal or industrial examples.

The tests are expected to prove the key components of the REGS geologic heat exchanger with stabilized, large fracture aperture and controlled flow zones for minimized opening pressure loss, seismicity and maximized energy extraction. The key to energy extraction is seen in creating zonal isolation of fracture flow by a grouted, blocking island between injection and extraction points of any planar fracture, forcing the coolant fluid away of the island to sweep large surface area of the planar fracture for heat exchange.

The paper reports preliminary results from laboratory-scale REGS tests and from a numerical simulation model of a conceptual, single-fracture REGS arrangement. The model results may be used in the 


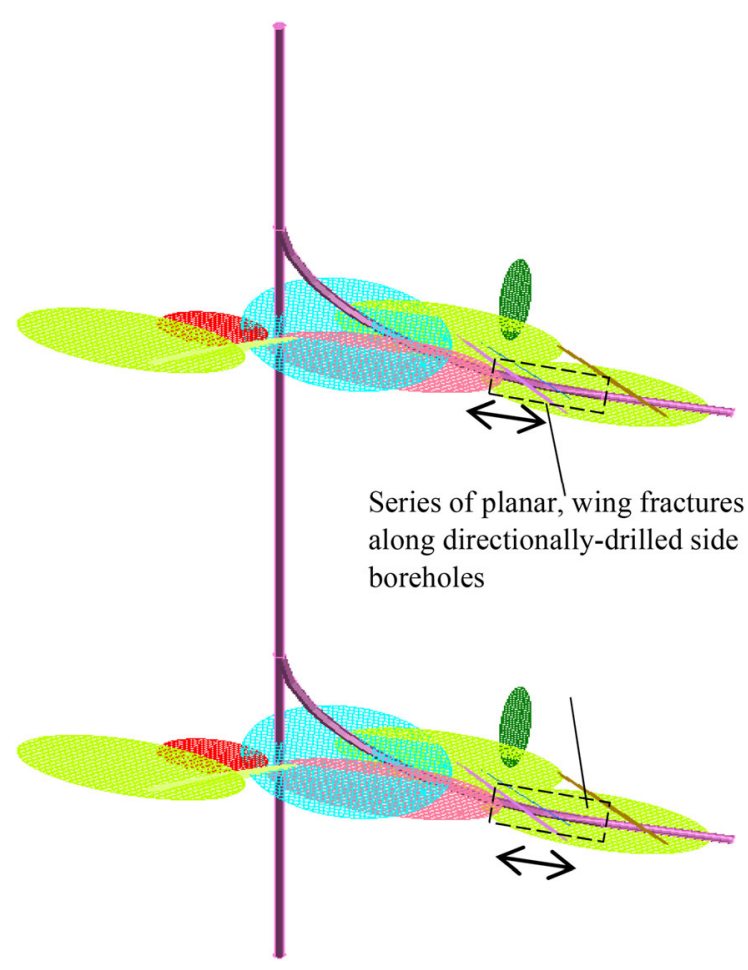

Fig. 2 Planar wing fractures along deviated boreholes

design of a field-scale experiment in a well drilled in hot, dry rock.

\section{Laboratory-scale tests of the physical model of REGS}

Laboratory-scale tests of certain elements of the REGS arrangement are conducted to move the concept closer to practical applications. Although much work has been conducted on wing fractures and their applications (Cornet 2016; Zhou et al. 2016), their application in the REGS arrangement needs experimental studies. There are many obstacles in creating a new system for the first time. Some critical elements are related to site characterization, directional drilling, and monitoring tasks, such as (1) drilling into the direction of an unknown fracture plane to be the osculating plain of the drilling section; (2) minifracturing testing for verifying directional accuracy during drilling; and (3) assessing the quality of flow connection between the well and its wing fractures during construction.
Challenges (1) through (3) are the tasks of drilling and fracturing experts and are considered solvable with technology developments driven by the oil and gas industry. There are specific challenges for REGS development, falling outside of the current, mainstream tasks of drilling for oil and gas. Such challenges are: (4) the completion of the planar fractures with the delivery of the grout into the desired area in the center of each planar fracture; and (5) reconnect the flow paths between the un-grouted fracture volumes and the well for coolant fluid injection and extraction for energy production from large heat transport surfaces. Further challenges are (6) the cost and financial feasibility of creating the REGS arrangement for field-scale application.

Preliminary grouting experiments were conducted in small-scale laboratory settings, emulating the opening of the fracture walls of the rock with two elastic plates as membranes. The goal of the experiments was to explore the controllability of the shape of the grouting island in vertical and inclined fractures with typically lens-shaped void space. Planar, lensshaped fracture apertures are commonly expected as a result of hydrofacturing for a geothermal energy reservoir (Kumar and Ghassemi 2016). An assembly of two stretched, elastic membranes was selected to closely approximate the lens-shaped void geometry opened by injection pressure for the grouting tryouts. In one experiment, a stainless steel plate of $0.87 \mathrm{~m} \times$ $1.07 \mathrm{~m}$ in size, $1.8 \mathrm{~mm}$ in thickness and a plywood plate of $12 \mathrm{~mm}$ thick, shown side-by-side in Fig. 3, were fastened together along their edges. The plywood plate was connected to injection and extraction ports as well as to pressure monitoring pipes, shown in Fig. 4 for the horizontal fracture experiment. The plates were covered with geotextile to emulate the roughness of the fracture wall.

The deflection of the plates under pressure load across the diameter was determined from the stretched membrane's equation (Hermida 1991). The fracture profile of opening due to the deflection of each side was calculated to be $5 \mathrm{~mm}$ and $7 \mathrm{~mm}$ for the stainlesssteel and plywood plates, respectively in the center location under 0.2 bar hydrostatic pressure. This value was found in excellent agreement with the thickness of the hardened grout island in the center point form the experiment. The measured deflection profile of the stainless steel plate was matched well from a 


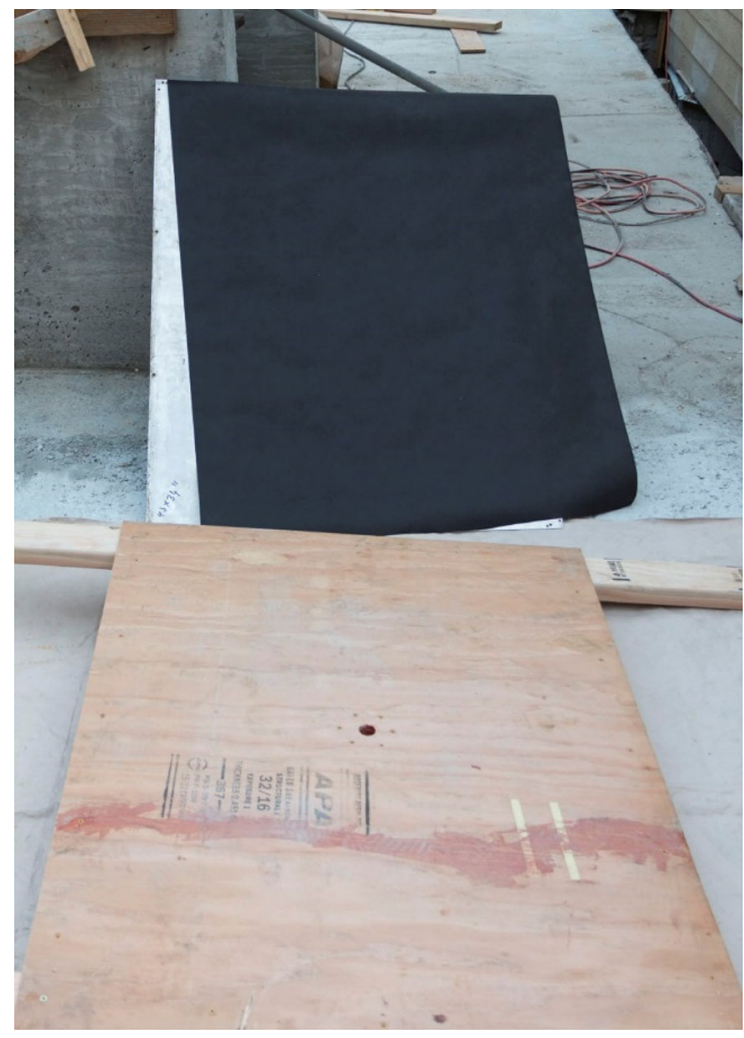

Fig. 3 The membrane plates for emulating fracture walls

published membrane equation solution (Hermida 1991), depicted in Fig. 5.

Injection of fast-setting water-cement grout in the horizontal assembly was performed under gravitational pressure through the central standpipe, shown in Fig. 4. The shape of the hardened, grouted island was found symmetrical and in the expected thickness from the membrane equation model. Based on the preliminary experiments, it is seen to be straightforward to control the size of grouted island by the volume and the viscosity of the mixture in a horizontal fracture.

A carefully engineered injection scheme will though be necessary to achieve an isolated, wellshaped, grouted island in the center of a vertical fracture. The vertical, stretched membrane assembly is shown in Fig. 6 for investigation. Several, commonsense ways have been explored to overcome the gravitation force that attracts the injected grout downward. One result is shown in Fig. 7, depicting a close-to-symmetrical grouted island shape, proving the possibility of achieving a desired shape by fluid and slurry flow engineering. Figure 8 shows the

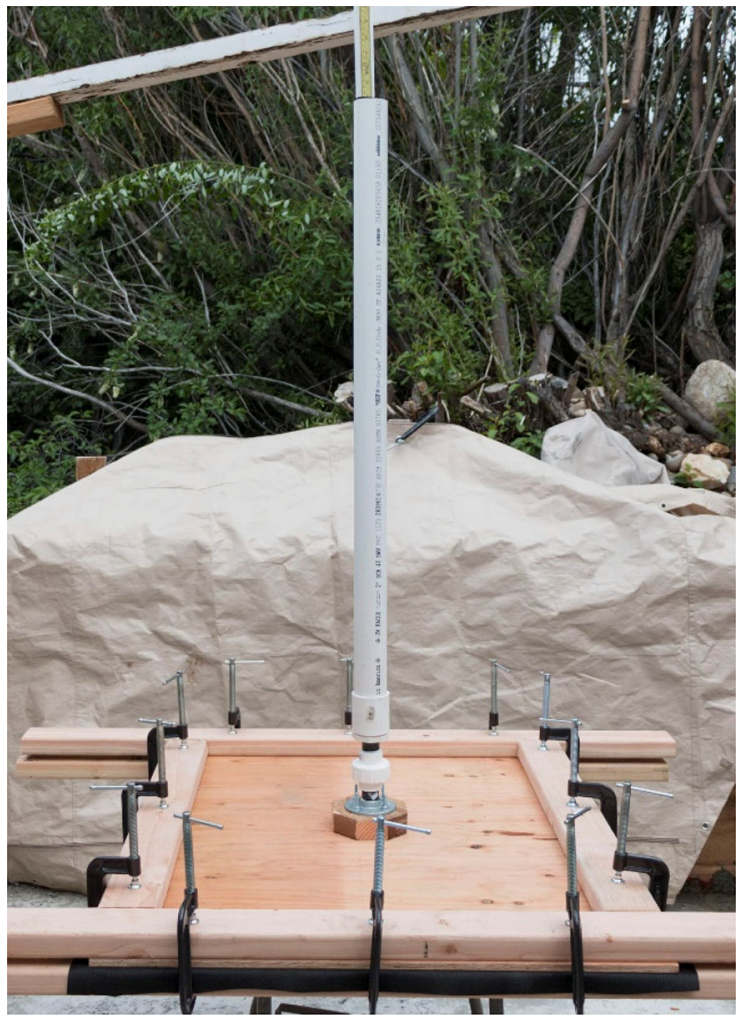

Fig. 4 The horizontal fracture grouting assembly

disassembled fracture walls and the still-attached grouting island through the stem hardened in the injection hole. More detailed, laboratory, experimental studies are underway in fluid flow and grouting injections at the University of Miskolc with an improved, stretched membrane assembly, shown in Figs. 9 and 10 in horizontal and vertical positions, respectively.

\section{Field-scale plans for thermal energy recovery with REGS}

The REGS arrangement still remains a concept and a hypothesis until it is tried out in the field. However, any field test of the technology requiring deep drilling and hydrofracturing, both expensive and unattractive due to perceived risks unless an overwhelming advantage for large-scale applications with potential financial gains. A preliminary, cost-benefit study is needed for the feasibility of a REGS field test. 


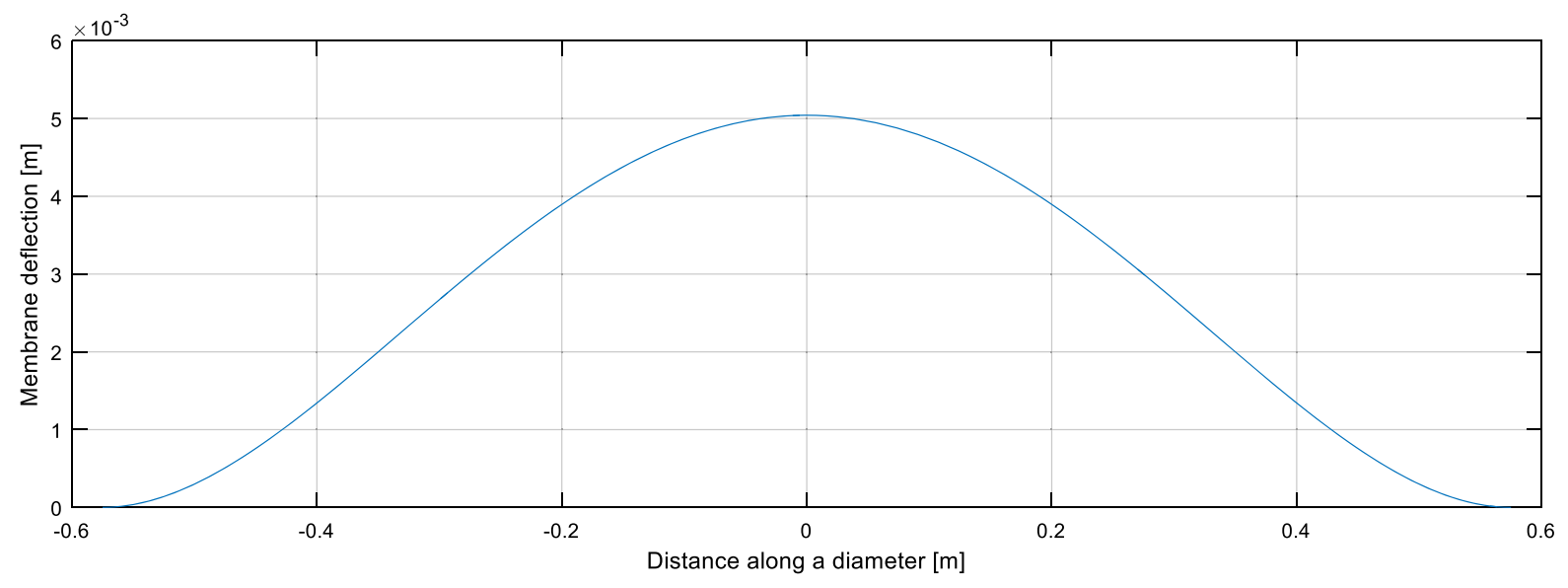

Fig. 5 Deflection profile of the stainless steel plate

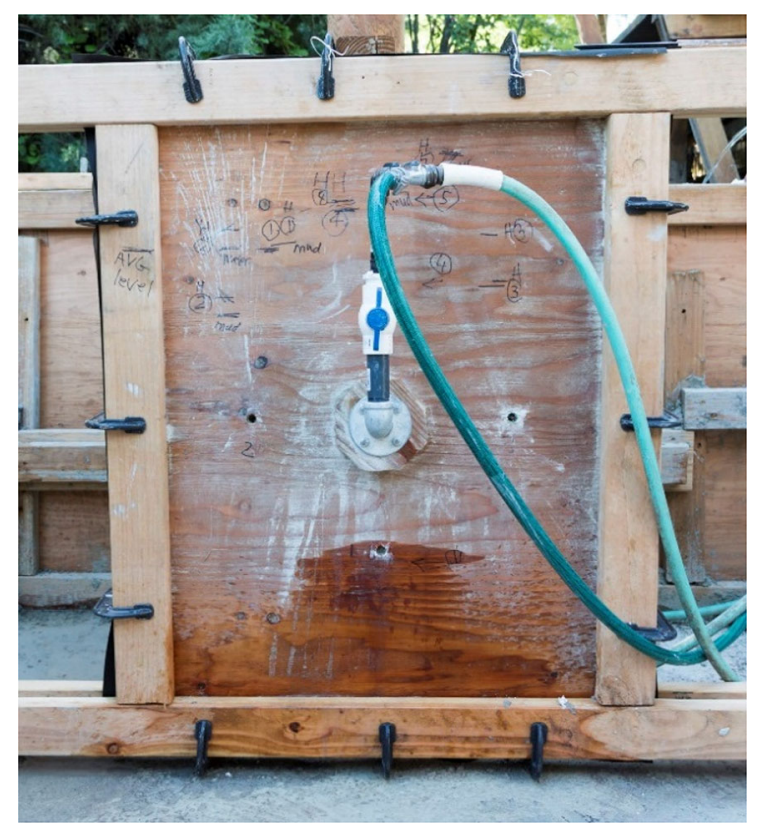

Fig. 6 The vertical fracture grouting assembly

The first step of such a study is presented for estimating the gross-value gain for a simplified and reasonable to implement REGS arrangement for the extraction of thermal energy from deep, dry, hot rock. A previous study (Danko et al. 2019) reported simulated thermal energy recovery characteristics from relatively shallow, exploited oil wells in sedimentary rock formation, available by the thousands around the word, for communal or district heating. The current study focuses on a site selection for a deeper and hotter reservoir. The current study assumes a deep

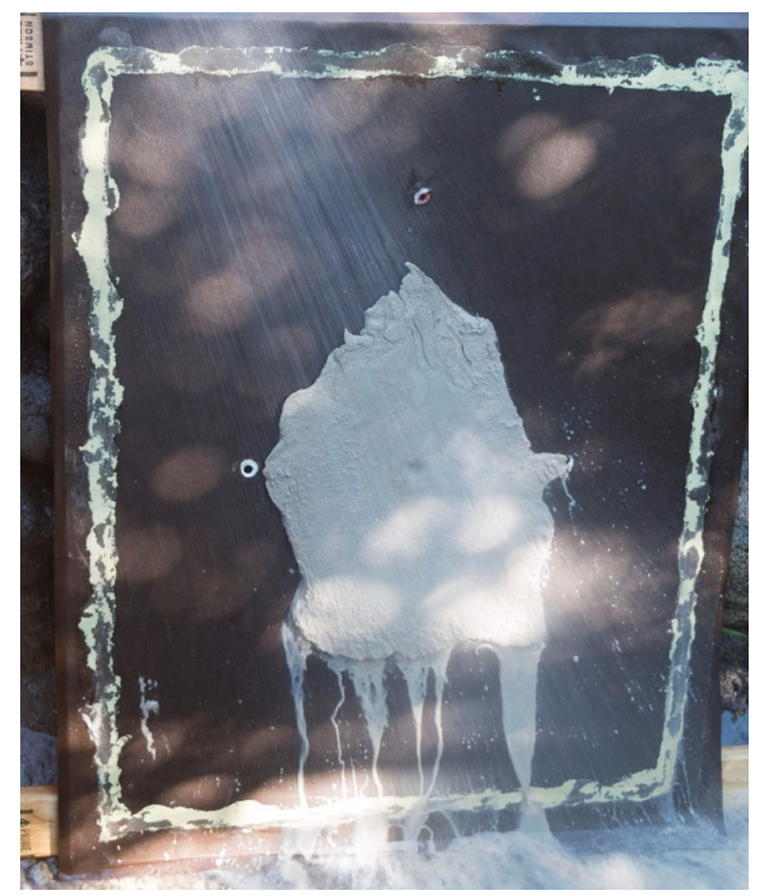

Fig. 7 The grouted island still attached to the separated wall

well driven in hot, crystalline rock formation at $160{ }^{\circ} \mathrm{C}$ at $5000 \mathrm{~m}$ depth. Homogeneous and isotropic material properties were assumed for simplicity of the first step study for the stated goal. The density, thermal conductivity, and specific heat for the rock formations are $2700\left[\mathrm{~kg} / \mathrm{m}^{3}\right], 3.5[\mathrm{~W} / \mathrm{m} / \mathrm{K}]$ and $980[\mathrm{~J} / \mathrm{kg} / \mathrm{K}]$, respectively. Although the assumed depth of the leading well into the conceptual REGS reservoir is $5000 \mathrm{~m}$ from the surface, the useful geologic heat exchanger area is around a relative compact, lens- 


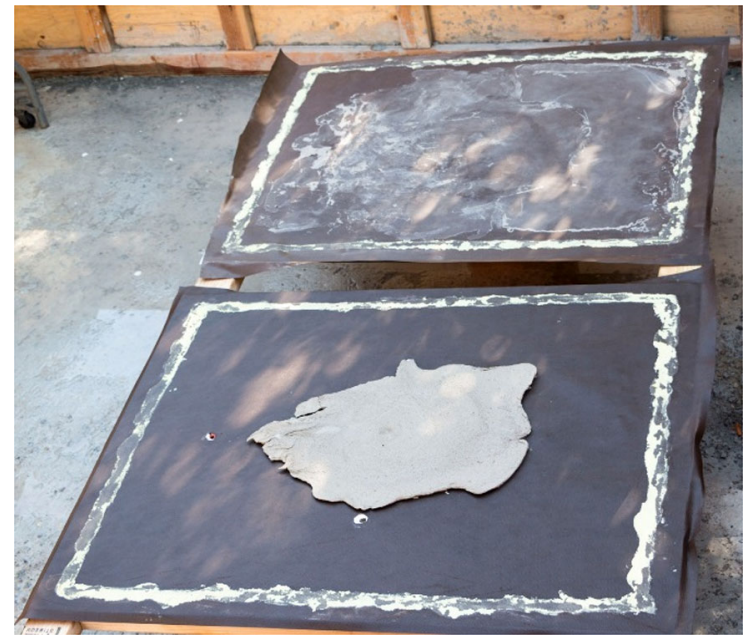

Fig. 8 The membrane walls of the grouting assembly

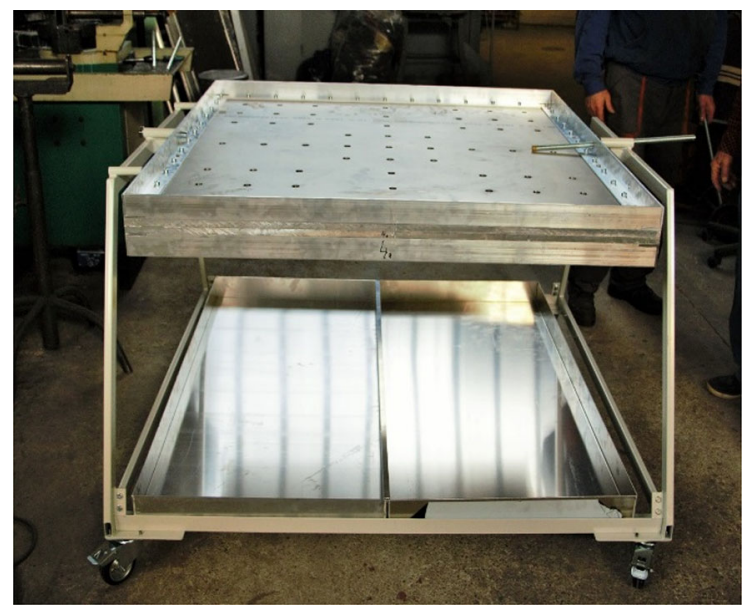

Fig. 9 The improved grouting assembly in horizontal position

shaped void space, only $600 \mathrm{~m}$ in diameter, stretching at the bottom to $5600 \mathrm{~m}$ depth. The schematic geometry of the REGS in a single-well arrangement is shown in Fig. 11.

The simplified REGS for Dry Well application is created in four steps as follows:

Step 1 A vertical, lined well of 5000 is assumed to be driven into a field with a horizontal, minimum principal stress field direction, expecting to result in vertical planar fractures, intersecting the vertical well along its full length, parallel with its axis as shown in Fig. 12. If this assumption is not proven by the data in the field from a mini-fracturing test, correction drilling along the actual fracture plain will be necessary for the

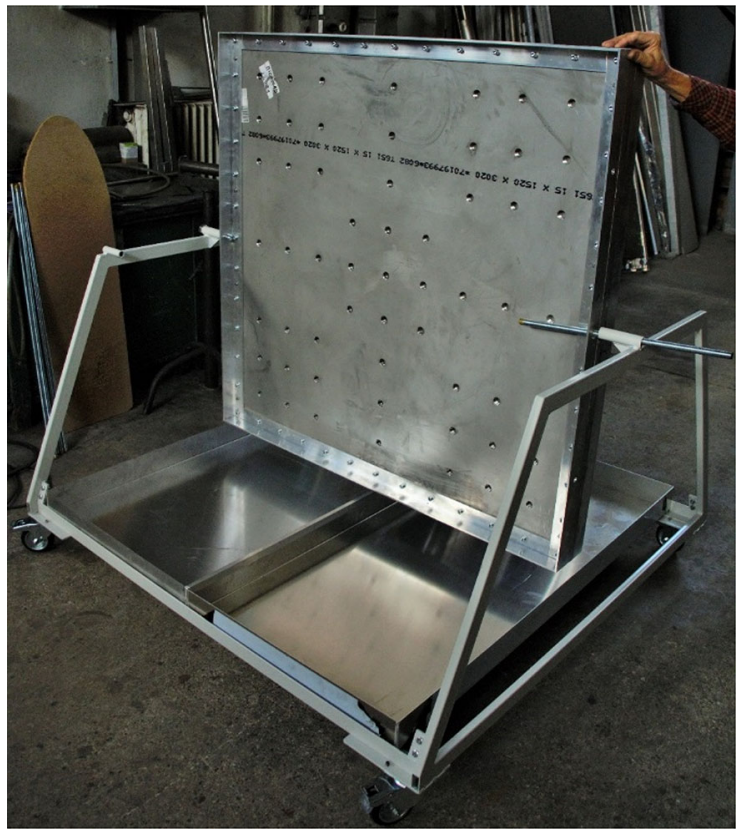

Fig. 10 The improved membrane assembly in vertical position

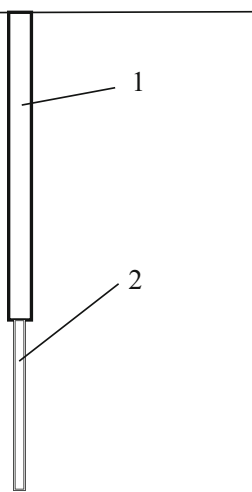

Fig. 11 The Dry Well (1 Lined Well Section, $2000 \mathrm{~m}, 7^{\prime \prime}$ diameter; 2 Open Well Section, 600 m, 6" diameter)

open well section, disclosed in detail elsewhere (UNR 2018).

Step 2 The middle area of the vertical, planar fracture is grouted through a grouting trummy pipe. Grouting starts from the bottom and moving upward the grout injection gradually. A short section is sealed on the lowest point to prevent grouting the bottom area of the planar fracture. The desired geometry of the grouted island in the fracture is shown in Fig. 13.

Step 3 The middle area of the grouted planar fracture and the bottom seal are drilled through to the bottom of the well for accepting the heated coolant 


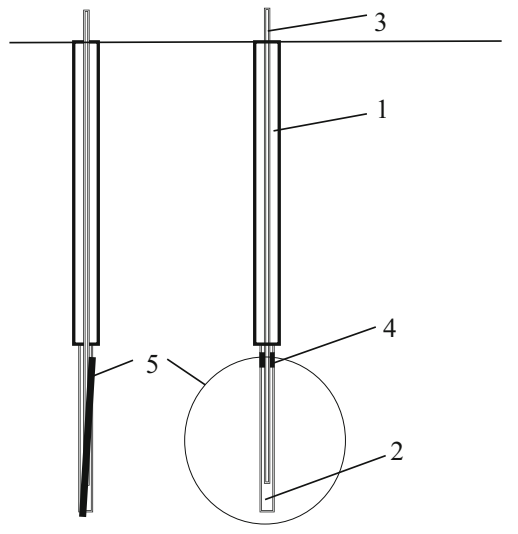

Fig. 12 Hydrofracturing the Dry Well (1 Lined Well Section; 2 Open Well Section; 3 Fracturing trummy pipe; 4 Pressure Seal; 5 Planar fracture in plain view and in side view)

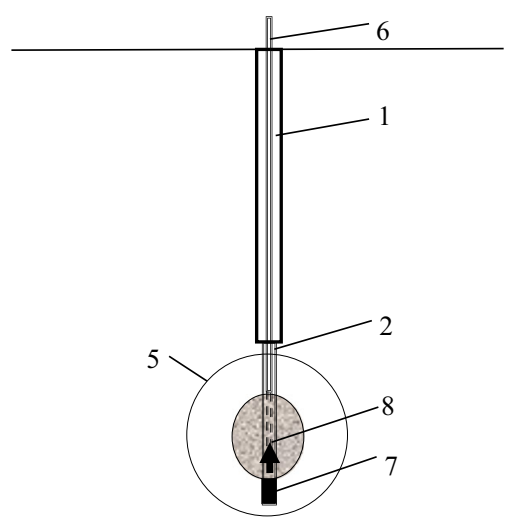

Fig. 13 Grouting the Dry Well (1 Lined Well Section; 2 Open Well Section; 5 Planar fracture in plain view; 6 Grouting trummy pipe; 7 Bottom Seal; 8 Grouting trummy pipe moving direction)

extraction pipe. After drilling, a circulation test is needed for assurance of hydraulic connection between the fracture void space and the two sections of the well for injection and extraction (UNR 2018). The test and mini-fracturing may be performed through the drill rod. The desired geometry of the coolant extraction pipe and the coolant fluid circulation system are shown in Fig. 14.

Step 4 A production pipe is inserted from the surface to the bottom of the well for coolant fluid recovery for geothermal energy extraction. The coolant extraction pipe is thermally-coated along its entire length and it is sealed through the grouted section after insertion to block the parasite interference with the

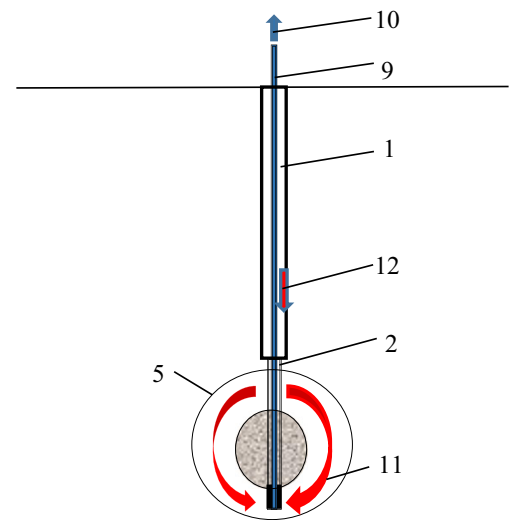

Fig. 14 Drilling and inserting the coolant collection pipe in the Well (1 Lined Well Section; 2 Open Well Section; 5 Planar fracture in plain view; 9 Coolant collection pipe; 10 Heated fluid; 11 Coolant-to-heated flow pattern in planar fracture; 12 Coolant injection fluid)

coolant fluid injection in the annulus between the well and the heated coolant pipe.

The conceptual arrangement is followed in the engineering model for quantifying the expected thermal energy capacity of the single-well arrangement. Instead of using a T-H-M model for the well-fracturerockmass system, a fixed geometry is assumed with three flow paths in the void space of the planar fractures. This way, it is possible to vary the coolant fluid distribution split between the three assumed pathways in the planar fracture for sensitivity check upon the thermal drawdown and energy capacity. The input data for three cases (Cases 1, 2 and 3) are given in Table 1, varying between cases only the coolant flow rate split between pathways 1, 2 and 3 .

\section{Mathematical model of REGS for energy recovery}

The geothermal module of the MULTIFLUX flow and thermal simulation code (Danko 2008; Bahrami et al. 2016) is used in the study to predict the expected thermal energy capacity of a single-fracture REGS arrangement. The coupled, T-H-M-C network model in MULTIFLUX is reduced for the present study to using only the T-H model parts whereas the mechanical model part is replaced with a fixed-aperture model, assuming a pre-defined, near-lens-shaped fracture cross section. The goal of the model simulation is to quantify the thermal capacity and thermal 
Table 1 Input data for dry wells

\begin{tabular}{llllc}
\hline Property & Case 1 & Case 2 & Case 3 & Unit \\
\hline Flow rate & 15 & 15 & 15 & $\mathrm{~kg} / \mathrm{s}$ \\
Injection water temperature & 30 & 30 & 30 & ${ }^{\circ} \mathrm{C}$ \\
Depth of lined well & 5000 & 5000 & 5000 & $\mathrm{~m}$ \\
Planar fracture diameter & 600 & 600 & 600 & $\mathrm{~m}$ \\
Rock thermal conductivity & 3.5 & 3.5 & 3.5 & $\mathrm{~W} /(\mathrm{mK})$ \\
Specific heat & 980 & 980 & 980 & $\mathrm{~J} /(\mathrm{kgK})$ \\
Density of the rock & 2700 & 2700 & 2700 & $\mathrm{~kg} / \mathrm{m}^{3}$ \\
Rock temperature at surface & 10 & 10 & 10 & ${ }^{\circ} \mathrm{C}$ \\
Rock thermal gradient & 0.033 & 0.033 & 0.033 & ${ }^{\circ} \mathrm{C} / \mathrm{m}$ \\
Coolant flow split in pathways & $22 / 33 / 45$ & $18 / 27 / 55$ & $8 / 25 / 67$ & $\%$ \\
\hline
\end{tabular}

drawdown for a 30-year time period for Cases 1 through 3 .

\subsection{The input parameters for the hydraulic and thermal models}

The main input parameters for the single-fracture, single-well model match those given in Sect. 4 and in Table 1. Furthermore, the maximum fracture aperture at the center of the fracture is fixed at $0.015 \mathrm{~m}$, tapered down as a lens shape to zero toward the edge of the planar fracture. This large aperture is made possible by the one-time fracture opening via a grout-injecting pressure overcoming the minimum principal stress in the rock strata.

The coolant fluid passes down in the annulus between the well's liner and the returning pipe, assumed to be $0.075 \mathrm{~m}\left(3^{\prime \prime}\right)$ in outside diameter, increased by thermal insulation of $0.02 \mathrm{~m}$ in thickness and $0.2 \mathrm{~W} /(\mathrm{mK})$ in thermal conductivity, a moderate value, assuming to be of a low-density, high-strength plastic coating of the $3^{\prime \prime}$ pipe. The thermal model of the downhole well includes heat convection between the downward coolant fluid and the well liner; and transient heat conduction in the rock around the well, cooling (or heating) the well from the outside. In the inside of the well, heat convection is modeled between the $3^{\prime \prime}$ pipe and the coolant fluid; heat conduction considered through the thermal insulation and the pipe's wall; heat convection included inside the $3^{\prime \prime}$ pipe between its wall and the upcoming hot coolant fluid; as well as heat advection is modeled inside the upstream flow.

The flow field in the planar fracture is assumed to be divided into three paths (Path 1, Path 2 and Path 3), discretized into grid cells, shown in Fig. 15. The length, width and surface area of each grid cell are depicted along each path in Figs. 16, 17, and 18, respectively. The total fluid flow is divided into these three paths as an input to the model, affected by the hydraulic resistances of the paths. Since no field data may be obtained for the split, nor active flow control is planned, sensitivity to the split of the total flow rate to paths is evaluated. An optimal split between the flow channels may be uniquely determined by matching a common exit temperature for Path 1, Path 2 and Path 3, maximizing thermal performance as a wishful outcome. The optimized flow rate splits between Path 1 , Path 2 and Path 3 were found to be $47 \%, 28 \%$, and $25 \%$, respectively for a previous example (Danko et al. 2019). Instead of following the optimum split concept, three variations are used, shown in Table 1 in Cases 1 through 3.

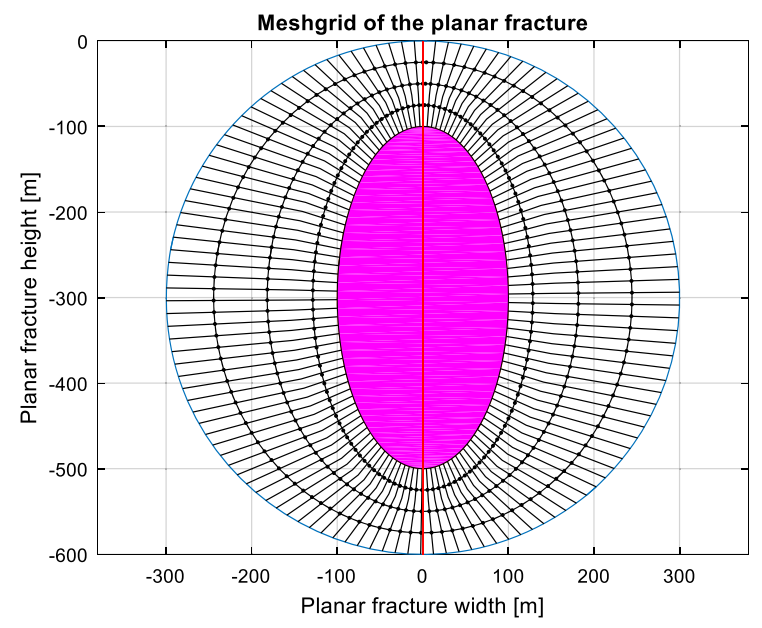

Fig. 15 Discretized fracture with grid cells 


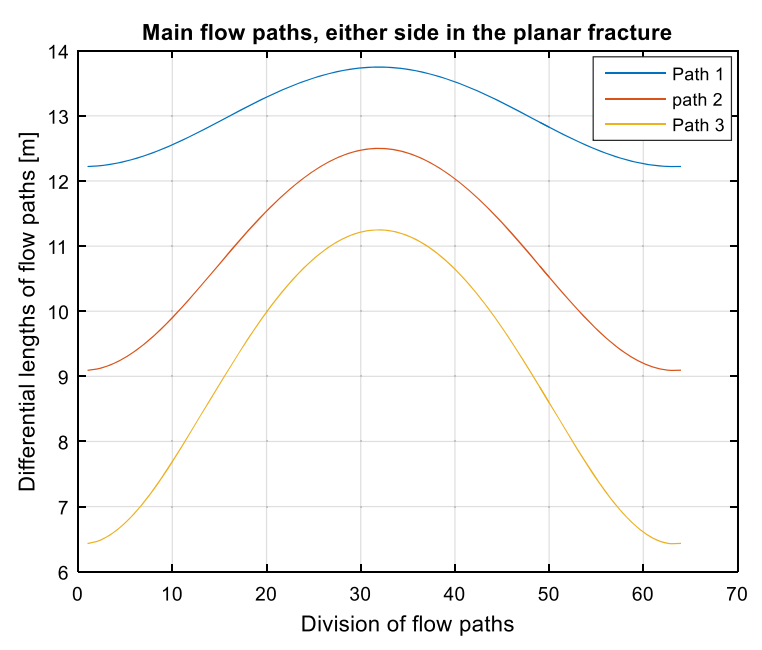

Fig. 16 The length of each grid cell along the flow path

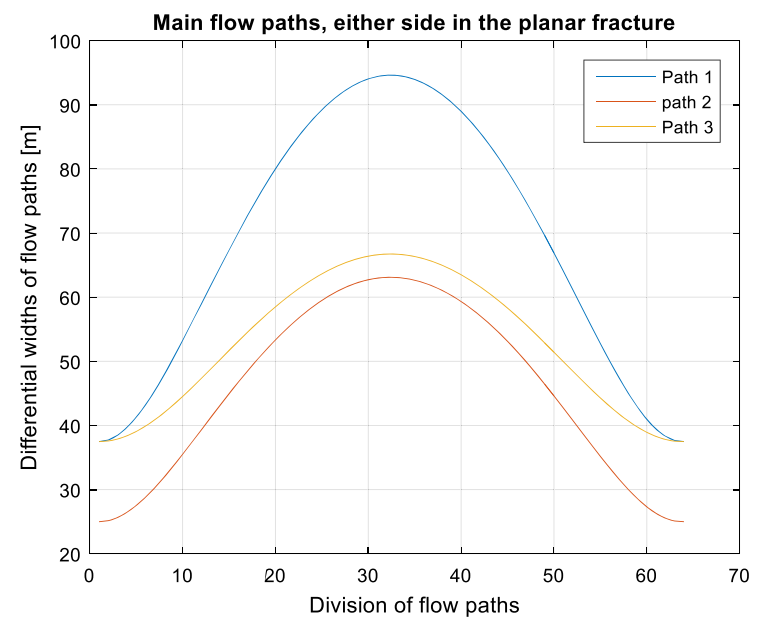

Fig. 17 The width of each grid cell along the flow path

The boundary condition in the heat transport solution between the hot rock strata and the coolant fluid is the Cauchy 3rd type in model.

Thermal connections between the grid cells are accounted for by advection, conduction and convection. Thermal connections between the grid cells and the rock strata include heat convection on the fracture surface; and transient heat conduction in the rock strata toward the undisturbed, virgin rock temperature that is a function of elevation.

\subsection{Numerical simulation results}

Fracture wall temperature fields, calculated from the numerical model along the flow paths of the coolant

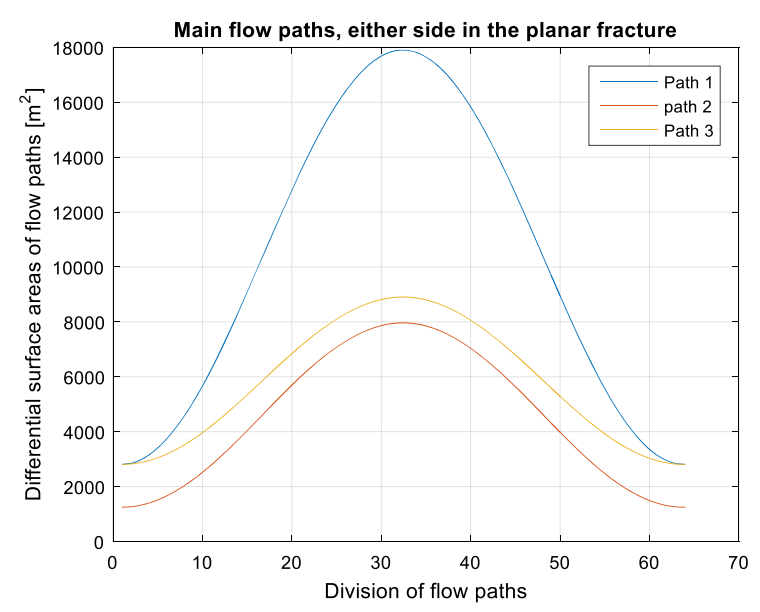

Fig. 18 The surface area of each grid cell along the flow path

fluid for Cases 1, 2 and 3 are shown in Fig. 19 for two time periods, Year 1 (left) and Years 30 (right). As shown, Case 3 represents a near-to-optimum fluid distribution situation as judged by the small difference between the exit temperatures of the coolant fluid leaving Path 1, Path 2 and Path 3 and joining together to the return section of the production pipeline at the bottom of the well at division node 164 .

The rock wall supplies the thermal power from the hot rock strata through three-dimensional transient heat conduction to the coolant fluid. The thermal power as total heat flux exploited from the hot rock of the REGS reservoir is calculated from the numerical model as a function of time, shown in Fig. 20 for Cases 1, 2 and 3. As shown, little effect on the power drawdown is caused by the actual fluid distribution split, a major advantage to robustness of the cooling system of REGS that may be otherwise unfavorably affected by a difficult-to-control coolant flow distributing in the planar fracture underground.

\section{Discussion of energy recovery application}

The hydrofracturing technology for REGS assumes a crystalline base rock formation (such as granite) with high mass density and thermal conductivity. The input parameters in the example represent such a formation. Many variables affect the simulation results for geothermal energy and power exploitation in a deterministic way. Variations, preferred choices or even optimization of the selected parameters may be easily 

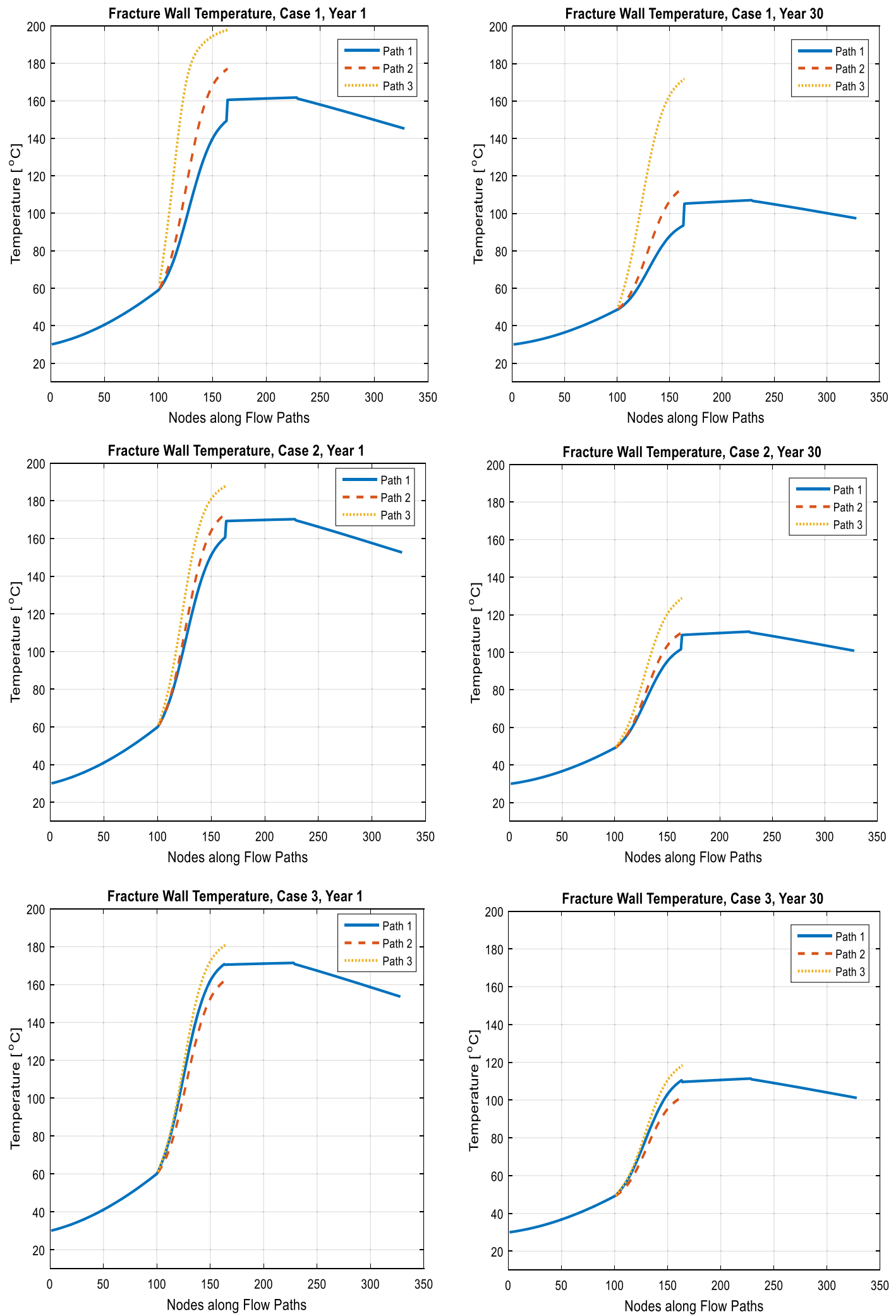
४Fig. 19 Temperature fields for Cases 1, 2 and 3 for Years 1 (left) and Years 30 (right)

studied with the MULTIFLUX model. Such details are omitted as insignificant for the issue of a typical energy potential for a realistic example. For a given site and design parameters, the model may be re-run for a detailed analysis to answer the "known unknowns." There still are "unknown unknowns" left in even the most carefully prepared simulation related to the flow field in the assumed planar geometry of the completed REGS fracture. The sensitivity to the unknown flow field distribution is studied by controlling artificially the split of the coolant flow rate into three main, perceived flow channels in the void space of the planar fracture.

The expected temperature distributions are shown as Cases 1 through 3 in Fig. 19 with three different split ratios and at two production ages of the reservoir, at Year 1 and Years 30 in the left and right columns. Only the temperature field of the rock-fluid interface is shown along the flow path starting at the wall of the downhole; splitting into Paths 1 through 3 at the wall of the planar fractures (showing three distinct lines with progressing flow path nodes); and joining and returning along the thermally-insulated production pipe wall in the annulus of the well. As the coolant fluid from the three flow paths merge into a common well section, their temperature will assume a common, mixed value according to the calorimetric equilibrium for their enthalpy. It is convincing to see that the temperature jump at node 164 for each path is reciprocally proportional to their mass flow rate as common sense expects it from the calorimetric mixing equation. It is also notable that the temperature in Path 3 in Case 1 nearly reaches its hypothetical maximum of the Virgin Rock Temperature (VRT) of $10+0.033 * 5875+203.9^{\circ} \mathrm{C}$ at that depth. Reaching the VRT would cause "thermal saturation," diminishing the heat transferring capacity of the flow path; however, this has not happened even in Case 1. It must be noted that the coolant fluid temperature distribution is found (but not shown for brevity) to be nearly identical with that of the rock wall due to a relatively high heat transport coefficient (and low thermal resistance) between the rock wall and the bulk temperature of the fluid at every node and time period. Therefore, Fig. 19 may be interpreted as a close equivalent to the coolant fluid temperature variation along the flow paths with space and time.

The independent variable of the temperature variation is the node number starting along the injection well through nodes (1100). Over these nodes, the rock wall and fluid temperature moderately increases due to the warming virgin rock temperature with depth and also amid the heat coming from the returning production pipe that runs upward in the well. The downward coolant flow continues in six parallel flow channels, three on the left and three on the right side of the symmetrical, planar fracture, illustrated in Fig. 15. The six parallel flow channels are represented by the
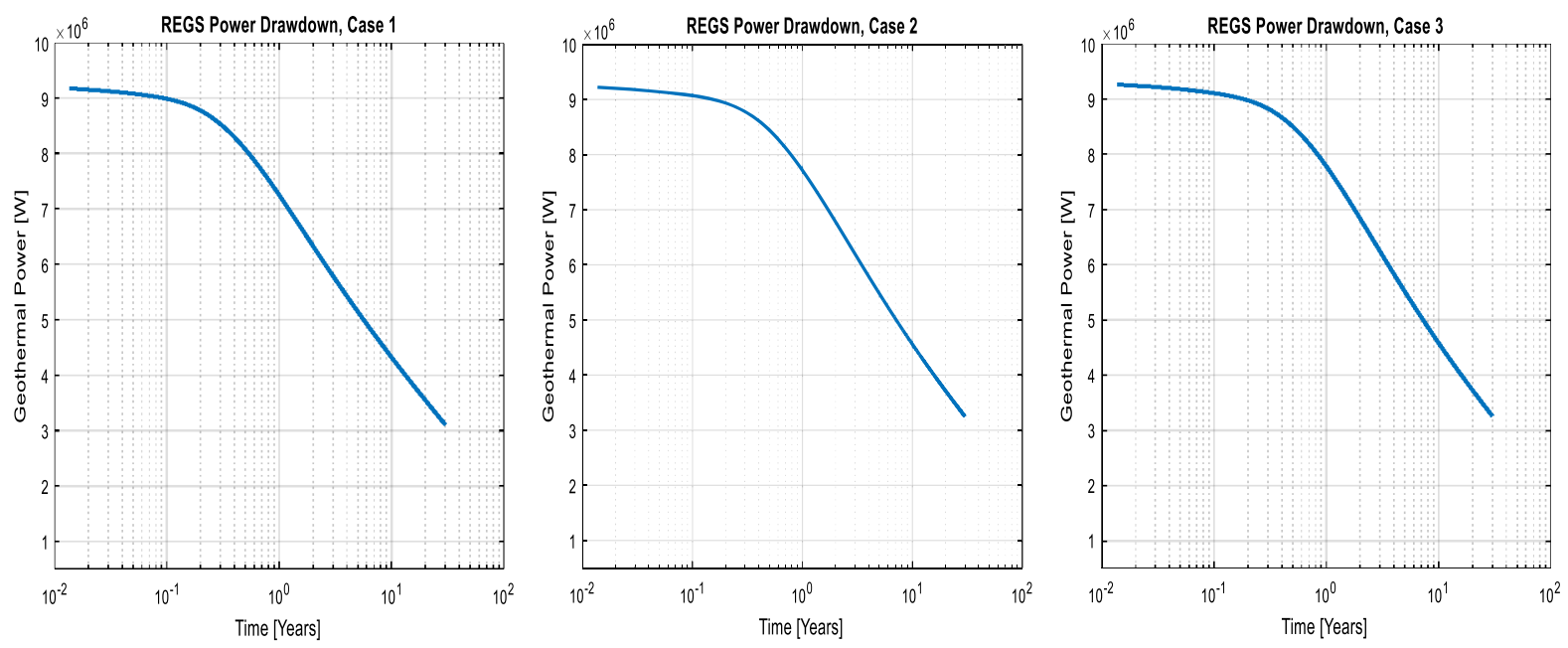

Fig. 20 Thermal power drawdown for Case 1 (left), Case 2 (center) and Case 3 (right) 
parallel resultant of three flow paths, marked as Path 1, 2 , and 3 through nodes $(101,164)$. These paths pick up the majority of the thermal energy, resulting in rapid temperature increase of the coolant fluid at the wall. The flow rate distribution between Paths 1, 2, and 3 greatly affect the rate of heat exchange as well as the temperature increase in the individual flow channels. As shown, the three temperature curves are different in various degrees according to the flow rate distribution splits; and that they are the closest to each other in Case 3, nearly matching the ideal mass flow split ratio determined in a previous study (Danko et al. 2019) in which case the temperature curves along the three paths would all overlap. Such temperature overlap occurs at node 100 before the coolant fluid splits into separate flow paths; and at node 165 after they merge in the coolant collection pipe at a common temperature.

From node 164, all paths merge into the first section of the upward production pipe through nodes 165 to 228 all in contact with the hot support island in the center of the fracture. The wall temperature and the coolant fluid slightly rises in spite of a declining virgin rock temperature with elevation, indicating a moderate gain of thermal energy especially at Years 30. The last section of the thermally-insulated production pipe runs through the center of the injection well for nodes from 229 to 328. Parasite heat exchange due to convection and conduction takes place between the cold injection and hot production fluids, heating and cooling them, respectively, along this section. The temperature variation with increasing elevation decreases slightly for the wall of the inner tube, replacing the rock wall for this section in the model. The temperature decrease of the wall (and inner-tube fluid temperature) is only a few degree Celsius due to the parasite heat exchange. It worth accepting a small temperature loss for the benefit of using $\mathrm{k}=0.1$ [W/ $(\mathrm{mK})]$, a moderately low thermal conductivity in the thermal insulation of the production pipe. Such a moderate thermal conductivity may be satisfied with the selection of a low-density, but metal- cladded plastic coating material that can likely withstand the insertion of a 5000-m long pipe section without suffering structural damage.

The thermal power drawdowns with time for Cases 1 through 3 are shown in Fig. 20. A low sensitivity to the fluid flow distribution ratio between Paths 1, 2, and 3 , is seen by comparing the power drawdowns in
Fig. 20. It must be noted that the T-H-M model MULTIFLUX, previously used for single-fracture EGS examples (Bahrami et al. 2016), is purposefully reduced to a simplified, T-H model. The coupled, T-H$\mathrm{M}$ model provides a unique solution for the flow field and remains mute regarding the sensitivity to flow field distribution along the fracture surface, a highly unknown variable and susceptible to geology variations. Using a simplified T-H instead of a fullycoupled T-H-M model and varying the flow distribution manually is shown effective to study the fracture flow distribution issue and to conclude that it is not as critical of a problem as it has previously been thought regarding a planar EGS arrangement.

All cases start with almost the same, higher than 9 MW thermal power for a few months of time, shown in Fig. 20. The power output gradually drops to close to $3 \mathrm{MW}$ in 30 years in all cases. The power outputs are not exactly the same for all three cases, but they are very close, an interesting feature due to robustness and insensitivity to the "unknown unknown" flow distribution variations in the fracture.

Nevertheless, the example demonstrates that a single fracture REGS arrangement can produce significant power and energy over 30 years, shown in Fig. 20 as a function of time for all three cases. The energy yield for all three cases is depicted in Fig. 21. The average rate of power output is around 4.2 MW even in the least efficient Case 1 flow distribution. The average power output may be converted to average $\mathrm{kWh}$ thermal energy, giving $4.2 * 8766=$ $36,817 \mathrm{MWh} /$ yearr or $36,817 \times 10^{3} \mathrm{kWh}$ energy per year for Case 1.

A gross value of the harvested energy is estimated to set a potential target, the first step only for analyzing the feasibility of the business case by an interested party. Assuming $\$ 0.07 / \mathrm{kWh}$ energy cost saving from heating with geothermal energy instead of electrical energy, the gross cost savings from electrical energy replacement is over $\$ 77.3 \mathrm{M}$ by applying a Case 1 REGS reservoir for 30 years. The cumulative thermal energy value yield is shown in Fig. 22 for Cases 1 through 3 as a function of the age of the reservoir.

Considering that the active, total surface area of the planar fracture in the example is $565,487 \mathrm{~m}^{2}$, the harvested power flux densities at Year 30 in Case 1 is $3100,000 / 565,487=5.48 \mathrm{~W} / \mathrm{m}^{2}$. This value is well over the natural, geothermal power flux density determined by the thermal conductivity and the 

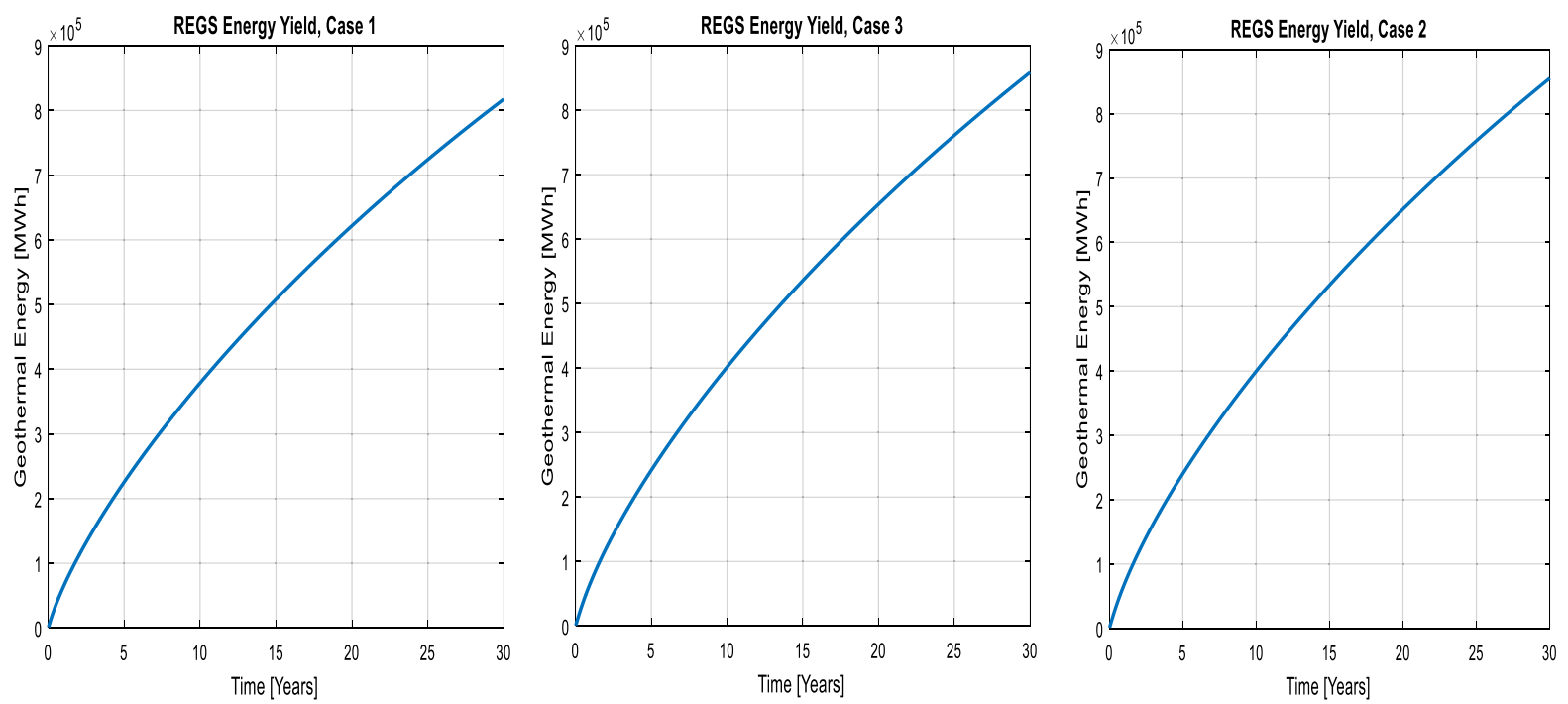

Fig. 21 Energy yield for Cases 1 through 3 as a function of the age of the reservoir
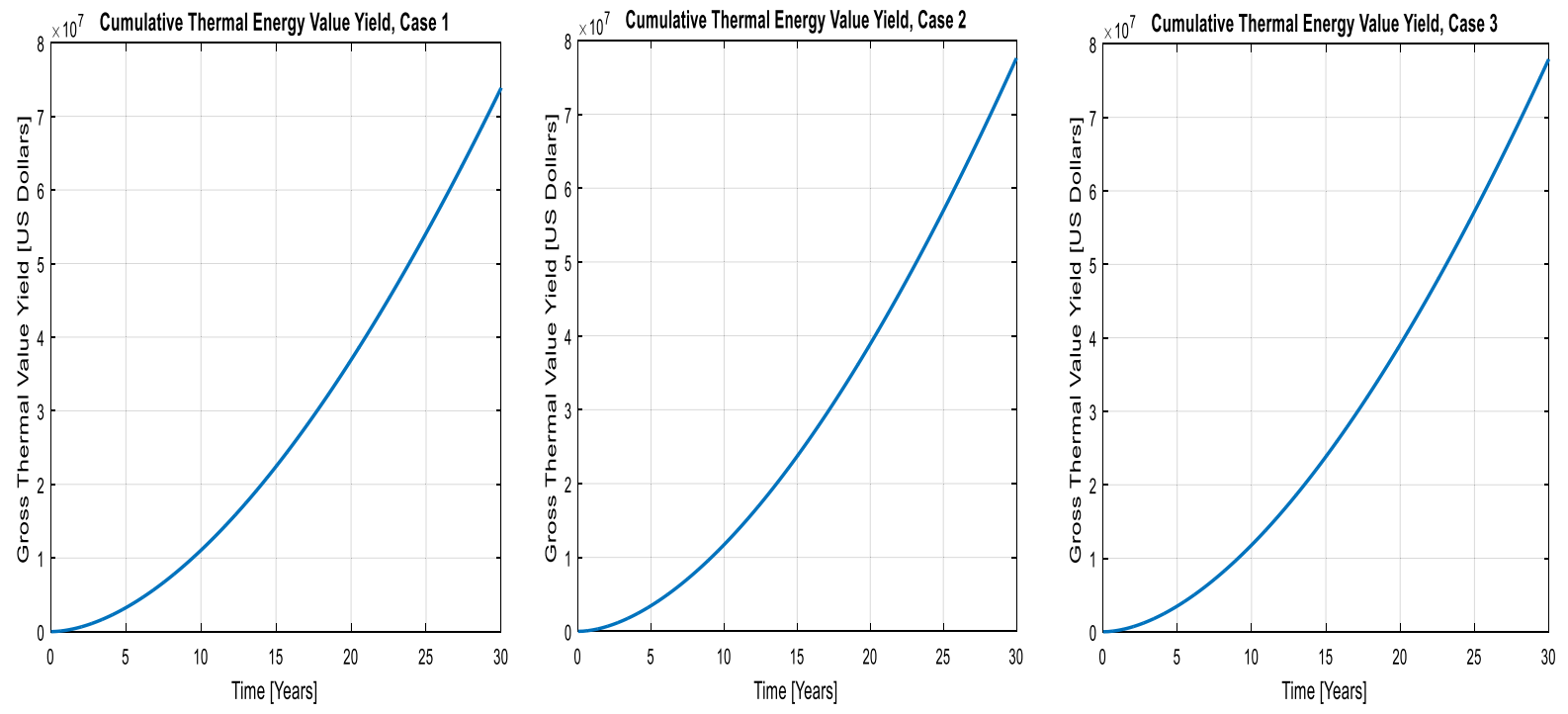

Fig. 22 Cumulative thermal energy value yield for Cases 1 through 3 as a function of the age of the reservoir

geothermal gradient as $q=3.5 * 0.033=0.1155 \mathrm{~W} /$ $\mathrm{m}^{2}$. The "collection factor," definable as the ratio, is 5.48/0.1155 = 47.5 for Case 1 .

\section{Conclusions and recommendations}

Test results are presented regarding a proposed, new EGS arrangement (called REGS) from examinations of its characteristics and expected uncertainties by computer simulation and experiments.
The geothermal energy extraction efficiency of the new REGS is presented for three cases in a simplified arrangement in order to support the feasibility considerations for field tests. The arrangement is reduced to a single well and a $600 \mathrm{~m}$ diameter planar wing fracture created from the well by hydrofracturing.

A low sensitivity to the fluid flow distribution ratio in the planar, wing fracture between Paths 1, 2, and 3, in Cases 1 through 3 is seen by comparing the power drawdowns in Fig. 20. This fact proves the robustness of the reservoir flow system to the "unknown 
unknown" in the field due to geologic variables. Numerical simulations show that an average, gross thermal power output of 4.2 MW may be harvested from a worst Case 1 reservoir for a 30-year operation time period. The gross market value of the geothermal energy that can be harvested form a Case 1 REGS-type reservoir is $\$ 77.3 \mathrm{M}$, counted at $\$ 0.07 / \mathrm{kWh}$ rate of energy cost.

The numerical simulation shows little temperature reduction and thus sensitivity to parasite heat exchange through the thermal insulation of the pipein-well fluid flow system in the single-well arrangement.

As an overall conclusion and recommendation, a REGS reservoir can be quite advantageous in view of its simplicity and economic potential, two factors in support for a field test.

Acknowledgements Open access funding provided by University of Miskolc (ME). The research was carried out with the support of the GINOP-2.3.2-15-2016- 00,010 "Development of enhanced engineering methods with the aim at utilization of subterranean energy resources" project of the Research Institute of Applied Earth Sciences of the University of Miskolc in the framework of the Széchenyi 2020 Plan, funded by the European Union, co-financed by the European Structural and Investment Funds.

\section{Compliance with ethical standards}

Conflict of interest There is no conflict of interest.

Open Access This article is licensed under a Creative Commons Attribution 4.0 International License, which permits use, sharing, adaptation, distribution and reproduction in any medium or format, as long as you give appropriate credit to the original author(s) and the source, provide a link to the Creative Commons licence, and indicate if changes were made. The images or other third party material in this article are included in the article's Creative Commons licence, unless indicated otherwise in a credit line to the material. If material is not included in the article's Creative Commons licence and your intended use is not permitted by statutory regulation or exceeds the permitted use, you will need to obtain permission directly from the copyright holder. To view a copy of this licence, visit http://creativecommons.org/licenses/by/4.0/.

\section{References}

Bahrami D, Danko G, Vazquez R (2016) Fracture and flow system modeling method for an EGS reservoir. In: Proceedings, thirty-eighth workshop on geothermal reservoir engineering, Stanford University, Stanford, California, pp 1-12

Cornet FH (2016) In-situ determination techniques and their robustness. In: GRC Workshop, Sacramento, CA

Danko G (2008) MULTIFLUX V5.0 software documentation qualification documents, Software Tracking Number: 1002-5.0-00, Software Management Office, Berkeley National Laboratory, pp 1-1002

Danko G, Bahrami D, Varga G, Baracza MK, Jobbik A (2018) Conceptual study of a well-fracture-well type fluid circulation system for EGS. In: Proceedings, 42nd workshop on geothermal reservoir engineering, Stanford University, Stanford, California, SPG-TR-213, pp 1-9

Danko G, Jobbik A, Baracza MK, Varga G, Kovacs I, Wittig V (2019) Demonstration tests of a robust engineered geothermal system. In: Proceedings, 43rd workshop on geothermal reservoir engineering, Stanford University, Stanford, California, February 11-13, SPG-TR-214, pp 1-12

DOE (Department of Energy) (2006) history of geothermal energy research and development in the United States, Reservoir Engineering 1978-2006. Geothermal Technology Program, pp 59-61

Hermida A (1991) Deflection and stress in preloaded square membrane. Goddard Space Flight Center. GSC-13367, vol 15 , No 9 , p 96

Jung R (2013) EGS-goodbye or back to the future. In: Effective and sustainable hydraulic fracturing. pp 95-112. https:// doi.org/10.5772/56458

Kumar D, Ghassemi A (2016) Hydraulic stimulation of multiple horizontal wells for EGS reservoir creation. In: GRC Proceedings, Sacramento, CA, pp 373-381

UNR (2018) US patent disclosure: (WIPO) Systems and methods for enhancing energy extraction from geothermal wells. International Publication WO/2017/173329 A1 (PCT/US2017/025473), pp 1-17

Zhou M, Cho J, Zerpa L, Augustine C (2016) Optimization of well in a sedimentary enhanced geothermal reservoir. In: GRC Proceedings, Sacramento, CA, pp 383-394

Publisher's Note Springer Nature remains neutral with regard to jurisdictional claims in published maps and institutional affiliations. 